\title{
AEROMAGNETIC MAP OF WESTERN PENNSYLVANIA AND PARTS OF EASTERN OHIO, NORTHERN WEST VIRGINIA, AND WESTERN MARYLAND
}

\section{By}

Peter Popenoe, A. J. Petty, and N. S. Tyson

\author{
GEOPHYSICAL INVESTIGATIONS \\ MAP GP-445
}

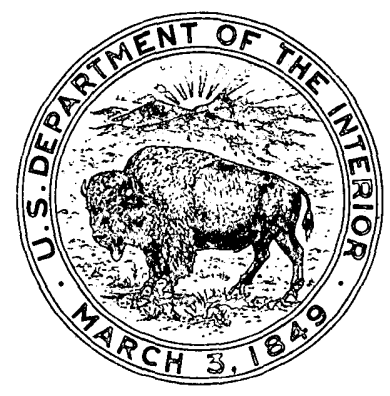

